\title{
An Exploration of Experiences and Academic Challenges of African Female Student at University of Zululand, South Africa (UNIZULU)
}

\author{
Ankur Tewari \\ School of Education, UKZN, Durban, South Africa \\ ankurtewari34@gmail.com
}

\begin{abstract}
Most African female students are weak in accounting. They feel that accounting is a male dominated subject. Studies have shown that females consider accounting to be masculine career. This study is an attempt to understand the academic challenges and experiences of African females at UNIZULU. With the aid of structured questionnaires, varied experiences and challenges of African female students at UNIZULU was captured and studied. Among the variety of experiences, few important ones are highlighted: academic support of lecturers, teaching and leadership style of lecturers, academic preparation of students, understanding of language and curriculum problems. In terms of challenges, students face problems related to language barriers, mathematical knowledge, time management, discipline and conduct, lack of female role model among others. The study suggested that UNIZULU should follow the gender sensitive leadership and mentorship programs to improve female academic performance in the accounting modules.
\end{abstract}

Keywords: Academic performance, Accounting, African female, challenges, Teaching, UNIZULU

\section{Introduction}

Accounting is perceived to be a masculine subject associated with masculine traits such as completion, accuracy, and mastery of numbers and mathematics (Broadbent, 2016). Many female students complain of prejudicial attitudes shown to them by males (Siboni et al., 2016). Females experience three main challenges as proposed by some studies such as Masasi (2012) and Spall (2012): (1) poor command of Emglish language (2) poor knowledge of mathematics (3) lack of good female role models. Males score better grades than females in these subjects and are more likely to become managers and earn more money than females (Spall, 2012). Males exhibit less anxiety as compared to females when doing accounting at university and are more confident in dealing with business and numbers; they are seen to be more assertive and competitive (Spall, 2012). However, females bring with them compassion and greater emotional intelligence to the workplace than males. They also take more personal responsibilities for than their male counterpart. The post-1994 period in the country has seen a sea change in handling the gender discrimination in the country. A Gender Equity Task Team (GETT) was created and the team recommended equal access to educational facilities without gender discrimination (Unterhalter, 2011). The South African government also introduced many interventions from schooling to the university education. The Thuthuka program promoted female enrolment and participation of African females in the discipline (Unterhalter, 2011).

Despite the extensive literature on the academic performance of female accounting students in developed countries, there is a paucity of qualitative and empirical studies in developing countries including South Africa. Masasi (2012) and others, such as Okafor and Egbon (2011) are a few scholars who have written and researched on academic performance and experiences of African females in accounting in African countries such as Tanzania and Nigeria, respectively. Understanding the educational psychology of female accounting students with respect to their experiences and challenges will curriculum experts to design gender-sensitive accounting curriculum in South Africa. The major objective of this study is to record, understand, and interpret the experiences of African females and the challenges that they face in completing the modules in the first year of the BCOM accounting program at the University of Zululand in KwaDlangezwa, KwaZuluNatal. The study aims to answer the following research question: why do African females struggle in the accounting modules? What African females experience in studying the first year accounting modules? What kind of challenges they face in this endeavour? The material of this study is organized under five sections. The Section 2 discusses the theoretical underpinning of the work and a brief review of literature. This is followed by the discussion on research methodology and data analysis in Section 3. The results are discussed in Section 4 while conclusions and policy implications are provided in Section 5. 


\section{Literature Review}

There are two main theoretical behaviour theories-sociocultural learning (SC) and neuro-linguistic programming (NLP). They provide the basis for understanding the psychology of the African females. Socioculturallearning theory is often based on the concepts of hegemony. It is derived from hegemon, literally meaning leader. This signifies some combination of authority, leadership and domination. In the context of this study, the group which is dominant and possesses authority and leadership are males and the subordinate group are females. Males dictate social norms and rules and females are expected to follow them. This theory states that males and females are socialized differently. Males are given more freedom to think for themselves and pursue any career they desire in the society. On the other hand, women are taught to be subservient and dependent on men for their happiness and wellbeing (Lander, 2014). The socio-cultural theory contends that female's reluctance and willingness to pursue careers in accounting due to socialisation. This theory provides the reason for poor female academic performance in terms of socialisation and the influence of parents and schools. It highlights the cultural reason behind the poor female academic performance in accounting. It may be possible that females are discouraged from doing accounting as they may see it as a male oriented career. This is due to parental and societal expectations of female students being home makers (Spall, 2012).

The teachers' attitude also matters in explaining the reasons for the poor academic performance of female students in accounting (Ansari and Bugden, 2010). This affects female students negatively and they have a low sense of self-esteem, which causes them to drop out of certain courses such as accounting. Teachers have an important role to play in the child's psychological and social well-being (Vogel et al., 2013). Children feel empowered and self-actualized when they have caring teachers so they can achieve their dreams (Vogel et al, 2013). This is true for female students who need extra nurturing and support from teachers to improve their academic performance in the accounting discipline. On the other hand, Neuro-Linguistic Programming (NLP) theory states that the neurons and brain network play an important role in explaining the learning behaviour. The neurons are responsible for memory, retention, and learning of new facts (Ansari, 2011). The brain is divided into left and right hemispheres. Each of these hemispheres has a function; namely, the right is used for numbers and logical things while the left is used for language, emotional understanding, and connections between things, people, and facts (Vogel et al., 2015). A few studies by Matjejo (2012), Vogel (2013), Vogel et al. (2013) analyse the brain structures involved in reading and mathematics. Matjejo (2012) looked at the neural foundations of arithmetic learning. The neuro-cognitive mechanisms that bind symbolic number processing and arithmetic are unknown. The study by Vogel et al. (2013), which used brain imaging research primarily using comparison paradigms, has provided strong evidence demonstrating that the Interior Posterior Lobe (IPS) in the brain is a key region for processing both numerical and non-numerical magnitudes. These studies have suggested that there are both activation overlap and segregation in these brain regions involved in processing different dimensions of magnitude.

As per socio-cultural learning theory, males and females are socialized differently and thus expected to behave differently in the real world. The subject of accounting requires good mathematical, analytical and language skills. Oftentimes, poor mathematical skills of females dissuade them from enrolling in accounting degrees. Accounting is hence considered as a masculine discipline (Masasi, 2012). Other factors that affect female student performance include, but not limited to the instructional style of lectures, gender, race and ethnicity. According to Masasi (2012), Spall (2012), and Roos (2009), female students tends to perform better academically when lectured by a female lecturer. The teaching style of the lecturers does impact positively or negatively on a student's academic career. In the study of Unterhalter (2011), it was revealed that female students are positively motivated by female lecturers (Unterhalter, 2011). Same gender identification is crucial or instrumental in determining the level of motivation in accounting (Unterhalter, 2011). Females are seen to be as more compassionate, kind and more emotionally intelligent than males, which are more competitive and sometimes rash and hot tempered (Unterhalter, 2011; Prakash and Flores, 1985). Male lecturers had a different teaching style than female lecturers; men were more relaxed in their approach and more complacent in their lesson preparation (Spall, 2012). They had a temper problem which caused female students to avoid male lecturers (Masasi, 2012). Men also displayed greater sarcasm and ridicule to female students (Masasi, 2012); they also had sexualized tendency towards women, which translated into bossy, authoritative and domineering behaviour (Unterhalter, 2011). Their mannerisms and behaviour also irked 
many female students who responded negatively in classes by not entering their classes or dropping out of the courses (Masasi, 2012).

Race and ethnicity play an important role in determining the effectiveness of teachers and students' performance (Spall, 2012). In post-apartheid South Africa, the teaching profession has become more diverse and more socially representative of the general population. During apartheid, the new ideals of learner centred education, inclusive and modern education, were mostly followed by white teachers. On the other hand, African and non-White teachers followed the traditional teacher centred teaching methods; the students had a limited idea of the curriculum as there was only one source of knowledge that was through the teacher alone (Spall, 2012). Lander (2014) also examined the race and ethnicity factors that determine the students' academic performance in commerce faculties in South Africa. The study had two important conclusions, namely: 1) African lecturers had a lower sense of confidence and self-esteem as compared to white lecturers; and 2) African students performed the worst at university commerce courses especially in accounting (Lander, 2014). This difference in students' performance can clearly be attributed to teachers' race and ethnicity. In conclusion, it is clear that lecturers characteristic influence students' emotion and affective attitudes towards the subject and this in turn influence the academic performance of students. A hard working, positive lecturer influences students positively so they earn better grades. A positive, friendly and well-prepared lecturer is always seen as desirable by students (Spall, 2012). Lecturers are always seen to be professional in the sense that they should be able to inspire students and inculcate positive values in them (Masasi, 2011). Female lecturers have a high stake in ensuring that female students are motivated to study and excel in accounting.

\section{Methodology}

A paradigm is a way of looking at the world through a prism. It defines hypothesis, perspective and research questions, aims, and objectives. This study used the interpretive paradigm in examining the experiences and challenges of African female students in accounting at UNIZLU as it is a preferred method in education discipline (Cohen and Manion, 1989). Interpretive paradigm aims at describing and interpreting the phenomena of the world and sharing this meaning with others (Pollard, 2002:32). In other words, the researcher tried to understand the meaning that people give to events, rather than from the researcher's perspective. The researcher employed the mixed method approach in this study. The mixed method research is a research methodology that combines the quantitative (for example, experiment, surveys) and qualitative (focus groups, interviews) research. The integration of both qualitative and quantitative research provides a better understanding of the research problem. The mixed method research also allows the possibility of triangulation; that is, combining several methods to examine the same phenomenon. Thus, this method provides a more comprehensive understanding of research.

Research Design: The research design of a typical study includes how the data is to be collected and what instruments are to be employed; some examples of research design include descriptive, correlational, experimental, semi-experimental, review of the literature and meta-analysis. These are some qualitative research methods. Examples of quantitative research methods are regression analysis and other multivariate statistical analysis. The current study used three types of research designs: (1) Review of literature technique, (2) Questionnaire-based survey. The review of literature technique was used as a research tool to describe the factors affecting the female academic performance in accounting challenges and experiences of females in studying accounting discipline at university. The other research design used was a survey-questionnaire. This entailed the collection of data by using survey questionnaires to discover the opinion of the intended population. Structured questionnaires were used as instruments to collect the opinions, attitudes and beliefs of African females about the challenges and experiences of studying accounting at UNIZULU. One popular method of data collection through surveys is using Likert scale techniques. Likert scale technique is used to measure attitudes of respondents by asking response to a statement which ranges from "strongly agree" to "strongly disagree"; this is a dominant method for measuring attitudes. Likert scale was hence chosen a method of analysis for the second objective of the study. 
Research Approach: Both qualitative and quantitative methods are used in the current study. The review of literature and survey questionnaire methods was chosen as a qualitative method. Descriptive statistics by means of bar charts and table were used in the quantitative method.

Population: The population of the study included first-year African female accounting students at UNIZULU in 2014. The location of the study was KwaDlangezwa Campus, University of Zululand. The entire population of accounting students is African; there were about 250 first year accounting students of which 120 were females. Most of these students were below 19 years of age and graduated from high school.

Sampling: This study used structured questionnaires to elicit information from students. The researcher analysed the academic experiences and challenges of selected African female students at UNIZULU for the year 2014-2015. Purposive sampling design was used and about 100 questionnaires were distributed.

Data Collection Tools: The major purpose of the structured questionnaire survey was to understand the emotions, behaviour and feelings of the students with respect to the teaching and learning issues within the accounting curriculum. A survey questionnaire was used as a tool for collecting data from the African female students. The questionnaire had two parts: Part 1 included responses to statements using a Likertscale; Part 2 included open-ended questions and opinions of the respondents. The survey questions were designed to keep all necessary issues in the mind. Ethical clearance was obtained from the University of Zululand Ethical Committee (UZREC), and also, permission from the Dean of Faculty of Commerce, Administration and Law was sought to collect information.

Data Analysis: The survey questionnaire data was tabulated from each questionnaire and was aggregated. A systematic analysis of survey questionnaires was used as a tool to collect the qualitative data about the experiences and challenges of African female students enrolled in accounting program. Responses from survey questionnaires were used to write down themes, norms and main ideas generated. For the quantitative aspect, graphical analysis by means of simple bar charts and simple percentage were used.

\section{Results and Discussion}

The researcher studied the experiences and challenges of first-year female accounting students. The research is based on the qualitative and quantitative analysis of the questionnaires administered to students at UNIZULU. For the qualitative analysis, the themes that were pinpointed from the literature review and also based on the information collected from survey questionnaire are discussed in Sections 4.1 and 4.2 while the quantitative analysis is discussed in Section 4.3.

Experiences: The student experiences can be classified into 6 categories of themes: (1) academic support, (2) career intentions and aspirations, (3) teaching and leadership style, (4) academic preparation, (5) understanding of language and (6) curriculum-related problem. There are briefly discussed here.

Academic Support from Lecturers: The majority of students surveyed in the study felt that lecturers were good and of a sufficiently high standard. A student commented, "I felt very blessed to be taught by such professional lecturers." They were happy with the academic support given to them. Many students felt that lecturers were professional and knowledgeable. Lecturers were seen as beacons of hope and transmitters of knowledge. They could motivate students to perform better on the subject. Students not only received academic, but also emotional and psychological support. They acted as emotional counsellors and agents who could understand the young students readily. Furthermore, students looked up to female lecturers as role models who acted as agents of change. The studies by Kadri et al. (2009) and Fried and MacCleave (2009) confirm that lecturer as role models positively impact the academic performance of students.

Career Intentions and Aspirations of Students: It is highly evident from the students' responses that they have an earnest desire to become CA's. Student A expressed the following words, "I have always wanted to be a CA, it is in my DNA." Student B stated, "Accounting opens up many avenues for financial success". Similarly, student $\mathrm{C}$ said, "I liked Maths and Accounting at school so I decided to study accounting so I could become a CA."Studies such as Spall (2012) and Pierre et al. (2009) have shown that accounting is indeed a difficult and 
financially rewarding career. Spall (2012) has argued that accounting is a rich subject fraught with technical jargon and difficulties. The majority of students felt that accounting is of prime importance in their lives. They are motivated by the subject and its high earning potential. It is believed that accounting is a highly sought after career and requires a lot of hard work and patience. A good knowledge of numeracy and language is essential for success in accounting. Most students have high aspirations and want to become high earners quickly. They want to enter top managerial posts in firms SAICA, KPMG and Ernst and Young.

Teaching and Leadership Style of Lecturers: The majority of students said, "my lecturer motivates us in the class". Another student commented, "Good leadership style is shown by lecturers and provides us with very kind of support we may need". This indicated that lectures were good in displaying good teaching and leadership styles. Most students stated lecturers were well prepared and emotionally sensitive. Students found their lecturers motivating and encouraging.

Academic Preparation by Students: Here are a few quotes from Students M and N which emphasise the need for good academic preparation that is needed by students. Student M stated, "Accounting is a tough subject and it needs a lot of preparation." Student N commented, "I have to prepare well for the degree, it is essential to prepare well for accounting exams and tests". "Reading before the lecture helps understand in the class" was a statement by student L. These quotes illustrate the need for good, sound preparation in accounting. Students have to be well prepared for accounting tests and examinations. The degree requires a high level of maturity and intelligence. The majority of students are extremely stressed out by the number of examinations and the syllabus. Students feel ecstatic when they pass the tests and examinations. In the context of the research study, there are a few South African and global studies which argue for excellent preparation needed by accounting students. It is noteworthy to see that scholars have emphasized the need of extensive tutorials, faculty intensive seminars and extra work schedules in order for students to succeed at accounting examinations.

Understanding of Language: Presently the medium of instruction at UNIZULU is English, but there is dissatisfaction expressed in their survey questionnaires. Students, in general, feel that the policy should change the medium of instruction to Zulu. The majority of students are thus experiencing cognitive dissonance as a result of exclusionist language policy. English is seen to be a language of the colonizer and foreign to many UNIZULU students. Students feel alienated by the lack of spoken Zulu in the lecture hall; they understand certain concepts much better in Zulu. They feel more comfortable with Zulu as they can understand the concepts better. Although English is the lingua franca of the South Africa, many staff and students are comfortable at teaching in and being taught in Zulu. Many socio-linguistics feel that the new government ought to implement the new language policy which called for indigenous languages to be used as mother tongue instruction (Spall, 2012). This is an essential step in transforming the nature of education in South Africa. With the possible introduction of Zulu as a language of instruction at South African universities, the higher education sector has to promote social justice and equality. Most students prefer Zulu as the first language to be the medium of instruction.

Understanding English language communication from a variety of lecturers amused students. Some students' mother tongue was not English, so they experienced some difficulty in pronouncing words and figuring out their meanings. "Students battle to understand the lecturers when they teach the students in English", said a student in the interview. Student M said, "Lecturers tried translating concepts into Zulu to make students understand. I kind of translate the idea in my language". Here are a few quotes from the students. Student P said, "I am a Zulu speaker, English is difficult for me to understand and write". Student Q: "English is a difficult language to understand and master. It is essential to understand English well enough to succeed in UNIZULU." Student R: "English is an essential skill needed at university. It is extremely difficult for African students to study in English medium university. The medium of instruction should change." All these quotes add to the complexity felt by students. It shows how most students feel that the medium of instruction should be IsiZulu. Furthermore, it is imperative to know English well enough to succeed at university (Foley, 2004).

Curriculum Related Problems: Majority of African students are extremely confused by accounting syllabus. They prefer to learn business economics instead. The typical examples to this claim are based on the survey done by the researcher. They also expressed difficulty in understanding the concepts of mathematics. Thus, 
poor knowledge of English and poor mathematical skills extremely constrain student's capacity to imbibe accounting concepts (Dafouz and Camacho-Miñano, 2016; Spall, 2012; Steenkamp et al., 2009). Students also need to develop synthesis skills. They need to follow their socio-cultural models of thinking and integrate all ideas in a cohesive manner. Based on the survey, the researcher noted that there are three main curricular related problems that accounting students at UNIZULU experience: (1) lack of understanding of accounting concepts, (2) poor knowledge of Mathematical and English skills, and (3) poor mentorship and application of the curriculum. Many accounting students are unable to synthesize the information presented in the curriculum. There is a poor understanding of accounting concepts by students. The curriculum is complex and requires a high level of mathematical and language skills. The following quotes from students X.Y.Z illustrate the following point effectively. Student X: "I struggle to synthesise the information and come up with unique solutions to academic problems." Student Y: "Synthesis of information is crucial in passing and doing well in Accounting." Student Z- "It is essential to be able to come up with holistic solutions to excel in accounting". Mentorship plays an important role in making students understand the insight related to the accounting.

Challenges: As discussed in the beginning of Section 4.0, challenges also constitute the part of the second research objective of the study. We, therefore, continue this discussion. Furthermore, the student survey indicated that female accounting students faced several challenges in pursuing accounting courses. The six notable challenges that students expressed were: (1) language barrier, 2) lack of knowledge of mathematical skills, 3) time management problems, 4) discipline, 5) poor control of skills, and 6) other miscellaneous ones. These challenges are extremely daunting for learners and are briefly discussed here.

Language Barriers: Language barrier affects students' academic performance negatively in the classroom. It is evident to see that the language barrier has a serious role to play in the poor academic performance of female students in accounting (Spall, 2012).It is an emotional issue for many students as they battle to understand the lectures in English. This is an interesting debate which should be an important question for language policy debates. It is important to promote mother tongue education as it is espoused by the South African constitution. Many students at UNIZULU have expressed dissatisfaction with being taught in English. They feel that Zulu should be the medium of instruction at UNIZULU. Zulu is thought to be a more representative language that they can relate to. Without repeating from section 4.1., many statements by students confirmed that English language skills are a must to be a good accountant which is in line with the study of Dafouz and Camacho-Miñano (2016) and Cole, Branson, and Breesch (2011). Language barriers are important in understanding female students' poor academic performance. African students have a poor command of English language and this is supported by studies such as Spall (2012), and Steenkamp et al. (2009). These authors argue that a poor knowledge of English causes poor academic performance in accounting. Second-language speakers of English are disadvantaged in examinations. It is historically an African university with a majority of students being African and coming from rural areas. Students feel comfortable conversing and writing in Zulu. They feel that it is important to teach in IsiZulu to make knowledge more accessible. Many African students see the importance of learning English as the lingua franca of the world and consider it a powerful language in the business world. Accountants need to have a mix of linguistic and commercial skills to become global leaders and agents of social change. Universities can play an important role in transforming the nature and medium of instruction. This can act as a catalyst that can promote social justice and equality. It is essential to promote values of social justice and multilingualism in South Africa.

Mathematical Skills: The problem of mathematics is common among many accounting students. Here are some students' quotes which express their mathematical anxiety. Student B "I battled with mathematics because it is difficult to understand. I battle with it." Other Student D said, "I really hated mathematics. I could not understand accounting". These quotes show how the student battles with mathematics and hates the subject. She feels inadequate about her lack of mathematical skills. Furthermore, the university needs to help the student to make them confident in their mathematical ability. Similarly, student $\mathrm{C}$ stated, "Mathematics is a tricky subject which needs some brains and is tough to handle". This quote strengthens the notion that poor mathematical skills are a problem among accounting students and they need to be helped in order to master mathematics (Muller, 2011; Okafor and Egbon, 2011). 
Time Management: Time management is an essential skill for university students. Donnelly et al. (2005) found that time management plays the most important role in student success at the universities. Time management is an important aspect of university study. Students who are poor managers of time fail miserably in their studies. The study mentions that time management and discipline is essential for employers. George et al. (2008) found that time management is the most important factor for academic achievement. The second study by Macpherson (2011) focuses on the academic performance of students studying in North American universities. These students were mostly conscientious and disciplined but some of them complained of poor time management skills due to girlfriend/boyfriend, poverty, the poor socioeconomic status of students and hunger. Many students came from a low socioeconomic background and battled to concentrate on studies. They also found it difficult to come and concentrate on university work. The presence of a partner also made it difficult for students to concentrate on their work and complete assignments on time. In the present context of the study, Student D commented: "Time Management is an important skill needed to survive in the faculty." It is essential to note that proper time management and planning is essential to succeed at university level accounting. This skill needs to be inculcated in students.

Discipline: Many students in the study felt that discipline is essential for success in the university. They feel the need to be disciplined so that they can achieve greater success in the working world. This attribute is essential to understand the nature of academic performance in UNIZULU. Discipline is essential in any field. Accounting requires an immense amount of discipline. It requires a strong sense of mind and willpower. The following quotes from students illustrate how important this attribute is. Student A's quote, "Discipline is needed if one needs to study and succeed in accounting". This explains how important the discipline is. There are many studies globally and in South African context that show how important it is to be disciplined. Koh and Koh (1999) and Spall (2012) have argued that disciplined students score well in accounting.

Poor Control of Skills: The research question relates to poor control of skills which adds to our understanding of how female students perform in accounting. As per review of the literature, there are three main difficulties that accounting companies face when they employ accounting graduates: (1) a poor knowledge of accounting and business terminology, (2) A lack of communication skills in business and (3) a poor knowledge and understanding of the business cycle. This is a global concern among top accounting companies who employ graduates in the field. These students state that it is difficult for them to master business communication and jargon because of a poor command of the English language. Communication skills are essential for entry-level accountants, especially newly appointed graduate. Similarly, poor numeracy skills also contribute to a lack of business mathematical skills. This is lacking in many UNIZULU graduates. If we analyse the lack of skills and poor control of accounting procedures, from a gender perspective, one can see that females tend to perform worse than male students due to societal and gender constructions. Society expects women to be nurturing and kind yet this is what impedes female professional growth. Females often have ambivalent feelings towards entering the business world and this is expressed by them in the survey. Student X - "I am unsure of myself in the business world". They have a self-fulfilling prophecy which causes them to feel insecure and incompetent.

Female Role Models: The presence of good female lecturers is an asset to the university. These lecturers are also a good example of gender equality which is espoused by the constitution. Female role models can be motivated by good mentoring from female academics. They can act as models of social change. Social change is an important aspect of gender relations at the university. There are some studies which show that good female role models can provide inspiring leadership students at UNIZULU. Jones (2013) found that supplemental instruction or mentorship (learning through peer group) can improve the academic performance of the students. Equally important is the career counselling for accounting students. These suggestions were to improve the nature of mentorship and career counselling for women. Career counselling for women is an essential part of her plan to improve the academic performance of female students. It is essential to see that increased participation of females in accounting would lead to greater diversity in the business world. There are a very few female accounting lecturers at UNIZULU. However, they lack organisational power and authority to implement social change. Female lecturers are instrumental in changing the perceptions of female students towards accounting as a subject. Empowerment of female lecturers thus finally leads to empowerment of female students in the discipline. There has to be a comprehensive training in gender equality and training so targets are achieved. There are many studies 
globally and in the South African context which suggests that it is essential for female academics to develop inspirational leadership and focus on improving female academic performance in accounting (Chishlom, 2001). The discipline requires good technical and emotional intelligence which females are good at and being with them to the business world. Similarly, a degree in behavioural sciences is necessary for students of business to master emotional and social intelligence which are seen to be vital for the business world.

Miscellaneous Challenges: Many female students have said that there are problems regarding their ability to synthesise information. They can understand individual concepts in accounting but struggle to focus and grasp the entire syllabus. They are unable to make connections between the syllabus and its main points. This is due to slow developmental growth and psychological problems. The slow connections between neurons and the two hemispheres of the brain play an important role in slow learning. Piaget (2003) argues that there is a lack of developmental outcomes in university students as many of them are in operating in formal concrete operational stage yet curriculum requires them to operate in abstract terms. University lecturers need to be aware of this developmental outcome. Lecturers also need to understand the role that secondary school teachers play in developing university students' intellectual and cognitive ability. The students need to ensure that they are developed into mature cognitively thinking adults who can contribute effectively to society.

Quantitative Analysis: Likert scale analysis is the other part of the questionnaire and is discussed here in this section. The responses were collected using the Likert scale (summated rating) techniques. This consisted of ten statements which were graded by the students in 1-5 scale, where $1=$ strongly disagree, $2=$ disagree, $3=$ neutral, $4=$ agree, $5=$ strongly agree. Descriptive information about the respondents is summarised and given in Figures 1, 2, and 3. Most of the respondents had an average grade of 4 or 5 in mathematics and an average grade 5 or 6 in English in the high school examination. The average age is about 19 years. The individual responses of 35 students are given in Table 1. The aggregate summated responses are summarised in Table 1.

Figure 1: Age of Respondents

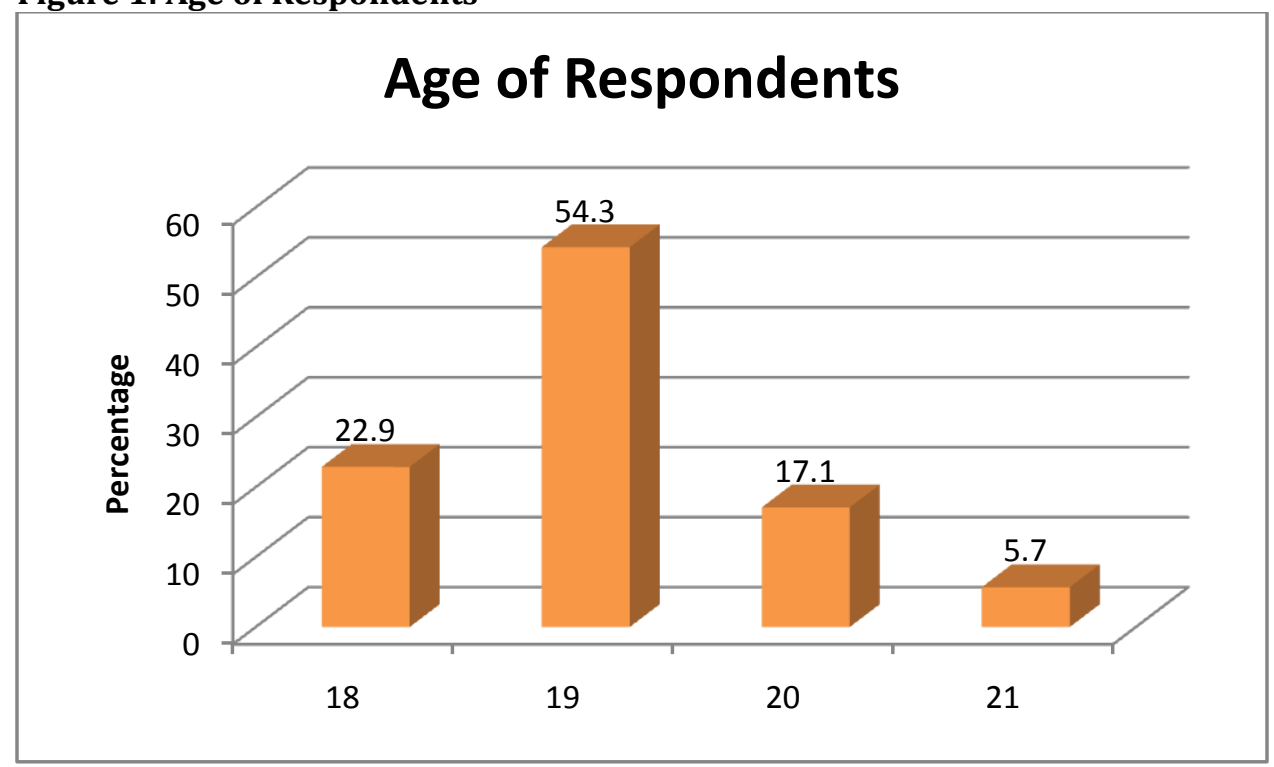


Figure 2: Respondents Score in Mathematics

\section{Mathematics}

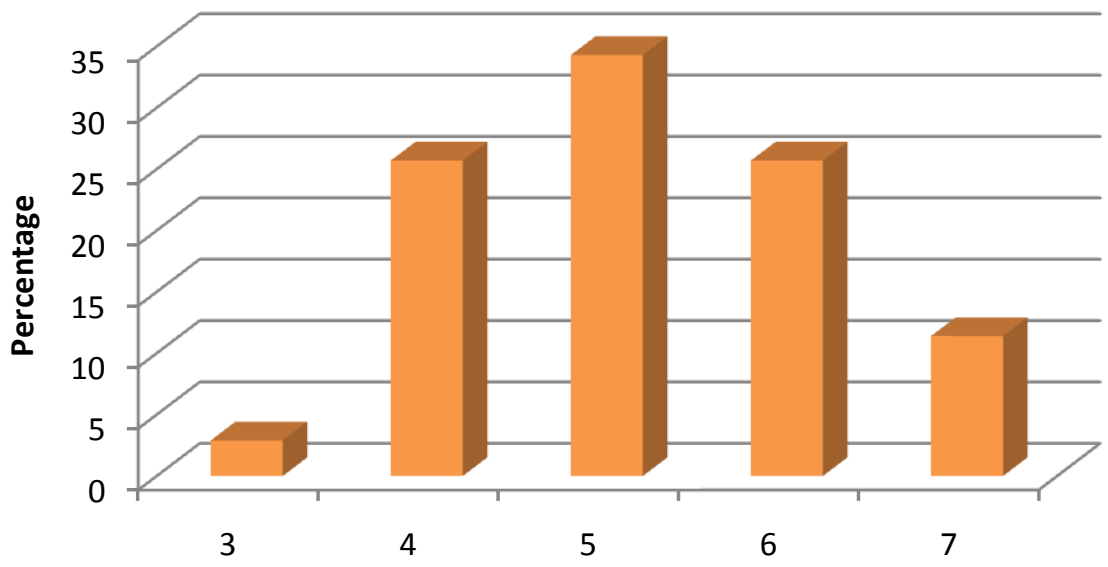

Figure 3: Respondents Score in English Language

English

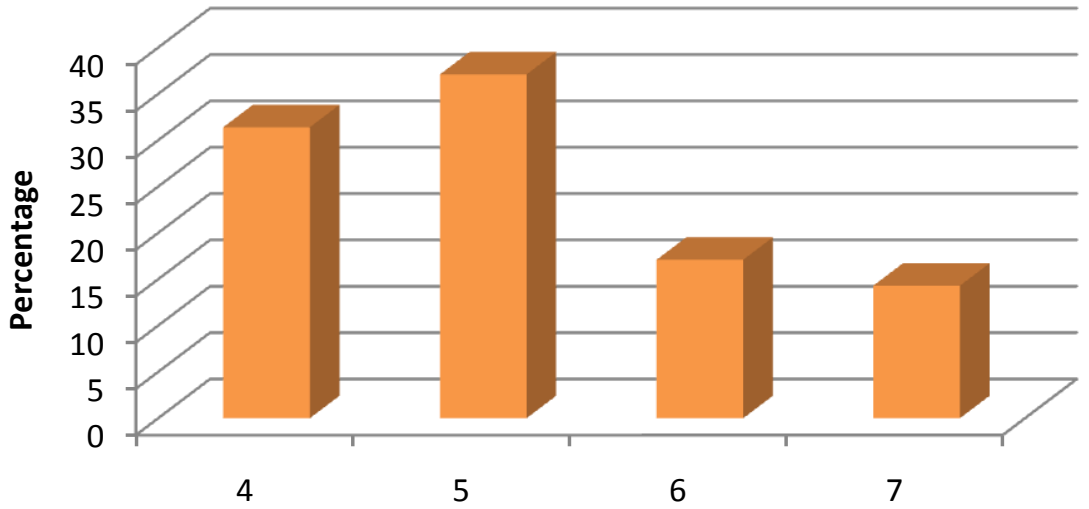

Table 1: Aggregate Responses of First Year Female Accounting Students, UNIZULU Responses Percentage

\begin{tabular}{lllllllllll}
\multicolumn{1}{r}{ Statement } & S1 & S2 & S3 & S4 & S5 & S6 & S7 & S8 & S9 & S10 \\
\hline Strongly disagree & 0 & 0 & 0 & 0 & 0 & 0 & 2.9 & 5.7 & 2.9 & 0 \\
Disagree & 20 & 0 & 5.7 & 2.9 & 11.4 & 14.3 & 8.6 & 14.3 & 28.6 & 2.9 \\
Neutral & 2.9 & 2.9 & 5.7 & 14.3 & 17.1 & 31.4 & 28.6 & 34.3 & 20 & 11.4 \\
Agree & 71.4 & 94.3 & 85.7 & 74.3 & 62.9 & 51.4 & 60 & 40 & 37.1 & 80 \\
Strongly agree & 5.7 & 2.9 & 2.9 & 8.6 & 8.6 & 2.9 & 0 & 5.7 & 11.4 & 5.7 \\
Aggregate Responses & 3.6 & 3.8 & 4 & 3.9 & 3.7 & 3.4 & 3.3 & 3.4 & 3.4 & 3.4 \\
\hline
\end{tabular}

Source: Author's Compilation

Note: Statement (1-10) 
- The content of Accounting lectures was difficult

- The content of the course requires a sound knowledge of Mathematics.

- A good knowledge of English is essential for attaining good marks in Accounting modules.

- Extra Mathematics Classes will help students understand Accounting concepts better and will enable students to earn better marks.

- Extra English Classes will help Students improve the Academic performance of students.

- Female Accounting lecturers teach better than male Accounting lecturers.

- Assessment of the Accounting course was fair and transparent.

- Female Accounting Lecturers understand the problem of female students much better than male Accounting lecturers.

- Female Accounting students are discriminated against by male lecturers in general.

- Good academic support was provided by the University.

Based on Table 1 as above, the majority of students surveyed indicated accounting as a tough discipline. For example, some 74 percent of respondents rated the statement number 1 (the content of the accounting lectures was difficult) as 4 or 5 ; meaning "agree" or "strongly agree" (Table 1). The average Likert score for the first statement was 3.6, indicating that most of the respondents agreed that accounting is a tough discipline. Some more than 90 percent of students agreed to the statements (Statement No 2 and 3) that the sound knowledge of Mathematics and good English language skills are the bare minimum to survive in the class (Table 1). For example, some 97 and 91 percent of students rated Statements No 2 and 3 respectively about 4 and above. For example, 34 out of 35 students (97.1 percent) agreed that mathematics skills are a must; likewise, 32 out of 35 (91 percent) confirmed that good English skills are very important (Table 1). It is interesting to note that research has shown that candidates who speak English as a first language tend to perform better in accounting qualifying examinations and degrees as compared to second language speakers (Roos, 2009; Koh and Koh, 1999). The need for good Mathematics and English skills are reinforced by statements number 4 and 5. Statements number 4 and 5 were tested on whether extra help with respect to these skills will enable them to do well in accounting modules. Some more than 86 percent of students questioned agreed or strongly agreed with the statements (Table 1). For example, some 32 out of 35 students, 86 percent of total, agreed that mathematics support enables them to do well in accounting. Likewise, some 32 out 35 students agreed that English skills do enable them to earn extra marks in accounting modules (Table 1).

This shows that academic support from the university is essential for students' academic performance. "There are many challenges that students experience such as the difficulty of curriculum, language difficulty and poor lecturers (Student A's words)". Furthermore, according to Student A "good leadership style is shown by the lecturers and provide us with every kind of support we may need. They are supportive." The teaching style also has a positive impact on the students' academic performance. There was a difference of opinion on whether female lecturers teach better than male lecturers or not (Statement No 6). The aggregate Likert score for this statement was 3.4, which was very close to neutral. That is, 19 out of 35 students rated the statement No 6 as 4 or above, some 54 percent of the total. The opinion here is thus almost split half and half. When the students were asked whether female lecturers understand the problem of female students better than male accounting lecturers, the response was not glaringly positive. Only 16 out of 35 students agreed or strongly agreed to the statement. This means that the majority of female students do not believe that only female lecturers can help them more than male lecturers. Unlike, Unterhalter (2011) who see female lecturers as more compassionate, kind and emotionally intelligent than their male counterpart, the respondents in this study opined that it is rather a person specific problem, not a gender specific one. Furthermore, only 49 percent of students felt that they are discriminated by the male accounting lecturers, the majority of female accounting students did not support that there exists any vehement gender discrimination against them in the class (Table 1, Statement No 9). This is contrary to the findings of Masasi (2012) who opined that men displayed greater sarcasm or discrimination to female students.Some 60 percent (21 out of 35 students) of student agreed that assessment of accounting module was fair and transparent (Table 1, Statement No7). Also, the majority of students questioned (86 percent, 30 out of 35 students) accepted that UNIZULU provided good academic support (Table 1). 


\section{Conclusion and Recommendations}

Education is seen as a tool for social change. Investigating the experiences and challenges of African female first year accounting students is very crucial for developing an appropriate framework that will improve their academic performance. Major challenges include language barrier, poor mathematical skills and poor time management. Accounting is seen as a difficult discipline which requires sound knowledge of mathematics and English language in order to excel, therefore, adequate academic support in mathematics and English language from the university, together with good leadership styles, are essential for excellent performance of the student in the course of study. Also, the majority of female students do not believe that only female lecturers can help them more than male lecturers. Rather, it is an individual specific problem. Taking cognisance of the peculiar challenges faced by female students, UNIZULU management has provided good academic support for them. It was established from the study that female accounting students perform less than their male counterparts and the major cause of such poor performance include poor mathematical skills. In order to solve such problems, this study recommends that a regular mentorship program, tutorship program and workshops should be put in place to improve their performance.

\section{References}

Ansari, C. \& Bugden, F. (2010). A critical study of neurons and their function on the brain. Journal of Neuropsychology and Cognition, 5, 89-105.

Ansari, C. (2011). The Differences between the two hemispheres and its impact on the neuropsychology and cognition. Journal of Neuropsychology and Cognition, 3, 88-106.

Broadbent, J. (2016). A gender agenda. Meditari Accountancy Research, 24(2), 30

Chishlom, C. (2001). Gender and leadership in South African educational administration. Gender and Education, 13(4), 387-399.

Cohen, L. \& Manion, L. (1989). Research methods in education. $3^{\text {rd }}$ Edition. London: Routledge.

Cole, V., Branson, J. \& Breesch, D. (2011). The illusion of comparable European IFRS financial statement. Beliefs of auditors, analysts and other users. Accounting and Management Information System, 10(2), 106-134.

Dafouz, E. \& Camacho-Miñano, M. M. (2016). Exploring the impact of English-medium instruction on university student academic achievement: The case of accounting. English for Specific Purposes, 44, 57-67.

Donnelly, D., Kovav, D. \& Fisher, D. (2005).The mediating effects of time management on accounting students' perception of time pressure, satisfaction with the major and academic performance. Social Science Research Network. Retrieved from http://ssrn.com/abstract=644582.Accessed on 25 March 2016.

Fried, T. \& MacCleave, A. (2009). Influence of role models and mentors on female graduate students' choice of science as a career. The Alberta Journal of Educational Research, 55(4), 482-496.

Foley, A. (2004). Language policy for higher education in South Africa: implications and complication. South African Journal of Higher Education, 18(1), 57-71.

George, D., Dixon, S., Stangal, E., Gelb, S. L. \& Pheri, T. (2008). Timed delay and questionnaire assessment of factors associated with academic and personal success among university undergraduate. Journal of American College Health, 56, 706-715.

Jones, P. (2013). The Impact of the supplemental instruction leader on student performance in introductory accounting. American Journal of Business Education (AJBE), 6(2), 87- 105.

Kadri, M. H., Alwi, F. \& Hashim, M. (2009).The effect of lecturer gender, teaching experience, and student gender on students achievement. Retrieved from http://ssrn.com/abstract=1458434 or http://dx.doi.org/10.2139/ssrn.1458434.

Koh, M. Y. \& Koh, H. C. (1999). The Determinants of performance in an accountancy degree courses. Accounting Education: An International Journal, 8(1), 13-29.

Lander, R. (2014).Racism in America. Race Ethnicity and Education, 14(3), 76-85.

Macpherson, A. S. (2011). Race and sex in North America. Journal of the American Ethnological Society, 38(3), 614-615.

Masasi, N. J. (2012).How personal attribute affect students' performance in undergraduate accounting course: A case of adult learner in Tanzania. International Journal of Academic Research in Accounting, Finance and Management Sciences, 2(2), 89-100. 
Matjejo, C. (2012). Approaches to research methods in experimental psychology. London: Palgrave Publishers.

Muller, J. (2011). Are Females being asked to do too much in the accounting field? Journal of Accounting and Financial Management, 7, 100-116.

Okafor, C. \& Egbon, O. (2011). Academic performance of male versus female accounting undergraduate students: evidence from Nigeria. Higher Education Studies, 1(1), 9-19

Paisey, C. \& Paisey, N. J. (2004). Student attendance in accounting module-reasons for non-attendance and the effect on academic performance at a Scottish university. Accounting Education, 13(1), 39-53.

Piaget, W. (2003). Piaget's Theory of Cognitive Development. Educational Psychology Interactive. Valdosta, GA: Valdosta State University. $\quad$ Retrieved from http://www.edpsycinteractive.org/topics/cognition/piaget.html.Accessed on 25 March 2016.

Pierre, K. S., Wilson, R. M. S., Ravenscroft, S. P. \& Rebele, J. E. (2009). The role of accounting educational research in our discipline-An editorial. Issues in Accounting Education, 24(2), 123-130.

Prakash, V. \& Flores, R. C. C. (1985). A study of psychological gender differences: applications for advertising format, NA-Advances in Consumer Research. Volume 12,Eds Elizabeth C. H and Holbrook, B. . Provo, UT: Association for Consumer Research, pp. 231-237.

Pollard, C. (2002). How meaning is created in interviews? Journal of South African Education, 6, 89-106.

Roos, S. (2009). Factors affecting Southern African students' success in CIMA examinations. Meditari Accountancy Research, 17(1), 49-67.

Siboni, B., Siboni, B., Sangiorgi, D., Sangiorgi, D., Farneti, F., Farneti, F. \& de Villiers, C. (2016). Gender (in) accounting: insights, gaps and an agenda for future research. Meditari Accountancy Research, 24(2), 158-168

Spall, N. (2012). Poverty and Privilege: Primary School Inequality in South Africa. Stellenbosch Economic Working Papers: 13/12 July 2012. A Working Paper of the Department of Economics and the Bureau of Economic Research at the University of Stellenbosch.

Steenkamp, L. P., Baard, R. S. \& Frick, B. L. (2009).Factor influencing success in first year accounting at a South African university: A comparism between lecturer' assumptions and students' perception. South African Journal of Accounting, Research, 23(1), 113-140.

Unterhalter, E. (2011). Progress made in gender equality in South Africa since 1994. Journal of Race, Gender, and Ethnicity, 4(6), 78-89.

Vogel, S. E., Gotten, C. \& Ansari, D. (2015).Developmental specialization of the left parietal cortex for the semantics representation of Arabic numerals: An FMR-adaptation Study. Developmental Cognitive Neuroscience, 12, 61-73.

Vogel, S. E., Grabner, R. H., Schneider, M., Siegler, R. S. \& Ansari, D. (2013). Overlapping and distinct brain regions involved in estimating the spatial position of numerical and non-numerical magnitudes: an fMRI study. Neuropsychologia, 51(5), 979-989.

Vogel, J. T. (2013). A case study on the impact of the READ 180 reading intervention program on affective and cognitive reading skills for at-risk secondary level students (Doctoral dissertation, Liberty University). 